American Journal of Applied Sciences 9 (9): 1390-1395, 2012

ISSN 1546-9239

(C) 2012 Science Publication

\title{
Acoustic Properties of Innovative Material from Date Palm Fibre
}

\author{
${ }^{1}$ Lamyaa Abd AL-Rahman, \\ ${ }^{1}$ Raja Ishak Raja, ${ }^{1}$ Roslan Abdul Rahman and ${ }^{2}$ Zawawi Ibrahim \\ ${ }^{1}$ Department of System of Dynamics Control, Faculty of Mechanical Engineering, \\ University Technology Malaysia, 81310, Skudai, Johor, Malaysia \\ ${ }^{2}$ Malaysian Palm Oil Board, Engineering and Processing Division, No 6, \\ Persiaran Institusi, Bandar Baru Bangi, 43000 Kajang, Selangor
}

\begin{abstract}
Problem statement: An organic material is one of the major requirements to improve living environment and the invention of materials need to consider for the best solution. This study presents an experimental investigation on pure porous from Date Palm Fibre (DPF). The effectiveness of sound absorbers depends on structural architecture of this material. This study was conducted to examine the potential of using date palm fibre as sound absorber. The effects of porous layer thicknesses, densities and compression on Acoustic Absorption Coefficient (AAC) of sound absorber using date palm fibre were studied. Approach: Rigid frame Johnson-Allard Model for various sample thicknesses was used in this study. The measurements were conducted in impedance tube on normal incidence acoustic absorption. The date palm fibre was mixed with latex which used for physical treatment on this material. Acoustic absorption behaviour of a porous material with different thicknesses was studied as well as samples with same thickness but different densities. In addition, samples with same properties but different period of compression time were inspected. The tests were in accordance to ISO 10534-2 and ASTM E1050-98 international standards for Acoustic Absorption Coefficient (AAC). Results: The experimental data indicates that two peak values of AAC is 0.93 at $1356 \mathrm{~Hz}$ for sample with 50 $\mathrm{mm}$ thickness, also the AAC at high frequency for same thickness is 0.99 at $4200-4353 \mathrm{~Hz}$ that means able to improve acoustic absorption coefficient at low and high frequencies with significant increasing. Meanwhile, another experimental results were acquired for AAC of date palm fibre, with samples thicknesses of $35 \mathrm{~mm}$ at different densities. The results show that denser sample $\left(11 \mathrm{Kg} \mathrm{m}^{-3}\right)$ has higher AAC value of 0.83 at $1934-2250 \mathrm{~Hz}$ as compared to less dense sample $\left(9.92 \mathrm{Kg} \mathrm{m}^{-3}\right)$ with AAC value 0.84 at $2443-2587 \mathrm{~Hz}$. Conclusion: Acoustic absorption coefficient AAC of date palm fibre was increased at all frequencies when the thickness of sample was increased, particularly at low frequencies less than $1200 \mathrm{~Hz}$. The introduction of latex on the samples adds stiffness, so that sound can be dissipated significantly as it travels through material. Results from the experimental tests show that date palm fibre has good acoustic properties at low and high frequencies and can be used as an alternative replacement to conventional product. Increasing density of the samples, increase the AAC as well. The innovative acoustic absorption panel has a good potential because they are cheaper and lighter in comparison to asbestos and rock wool industrial materials.
\end{abstract}

Key words: Acoustic absorption coefficient, date palm fibre, layer thickness, density

\section{INTRODUCTION}

A comfortable environment free from noises has always been a dream in every society. Noise can be considered as one of the seriously environmental issues, which causes many problems, such as effect on health, communication, hearing loss, changes in human behaviour and sleep disturbances. Few decades ago industrial materials such as rock wool, glass wool and asbestoses have been introduced to reduce noise level especially in workplace. However, these materials can lead to many serious health issues such as lungs, eyes, skin and other problem .Recently, few researchers have found alternative materials which are friendlier to human health than previous materials (Lee and Swenson, 1992; Joshi et al., 2004).

Natural fibre is one of the alternative materials to be used as acoustic absorption material. Natural fibre can be found in agriculture naturally and renewable in abundance. It is also lot cheaper than the previous

Corresponding Author: Lamyaa Abd AL-Rahman, Department of System of Dynamics Control, Faculty of Mechanical Engineering, University Technology Malaysia, 81310, Skudai, Johor, Malaysia 
mentioned material and has many advantages in the application of acoustic treatment.

A lot of researchers have investigated the potential application of these natural materials for acoustic treatment. Wassilieff (2003) demonstrated that the incidence of normally sound absorption for wood depends on porous, tortuous, air flow rate and layer thickness. On the other hand, Yang et al. (2003) investigated the application of rice straw- wood for absorption of sound to preserve temperature within structural building instead of wood particleboard. On the same year Khedari et al. (2003) developed agricultural naturally abundance material, to be used for sound absorption particle boards, Zulkifli et al. (2008) was as well succeeded in applying the same wastes for this particular purposes. They both found out that the porosity of rice straw-wood is far better than woodbased substitute since the specific gravity of this material is lower. The useful or effective frequency range for this material is between $500-8 \mathrm{KHz}$.

Study on the acoustic characteristic of this material shows that the porosity and density of this material change the acoustic impedance and absorption coefficient of the acoustic absorber considerably (Davern, 1977). The porosity of substance depends on the propagation of wave and properties of impedance which can be expressed as resistivity of the flow, number of wave, density of air and frequency of sound, (Delany and Bazley 1970).While, achieving desirable characteristic for absorption sound, through the porosity of the substance, the ability of construction and flow resistivity(Lee and Chen, 2001).

Other researchers (Ersoy and Kucuk 2009) investigated the waste substance from tea leaf fibre in various thicknesses by using woven textile cloth for backing of the acoustic absorber characteristic. They found from the experiment that tea leaf layer waste having thickness of $10 \mathrm{~mm}$ with backing has absorption sound equal to six layers of woven textile cloth having thickness $20 \mathrm{~mm}$ at the same frequency range 500-3200 Hz.

Wang and Torng (2001); Hong et al. (2007) have investigated the porosity of synthetic materials via thick layer to improve efficiency of acoustic absorption at lower frequency. They found out that structural mixed of perforate plate, rubber small piece, porosity substance; polyurethane (PU) foam and glass wool distinctly promote reduction in the acoustic absorption. This research was undertaken in an effort to study the properties of date palm fibre for the purpose of replacing synthetic and mineral based fibres in the application of acoustic absorption. This study looked into the effect of thickness layer, densities and other effects on the sound absorption coefficient of the date palm fibre as sound absorber.

\section{MATERIALS AND METHODS}

In this study, date palm fibre is user as the main raw material. Date Palm Fibre (DPF) sample is treated with latex during forming process in order to coat the date palm fibre without changing the structure of the fibre sheets. Two different diameters of samples were used for testing, $28 \mathrm{~mm}$ for higher frequency and 100 $\mathrm{mm}$ for lower frequency. Impedance tube consists of two steel rods of $100 \mathrm{~mm}$ length which used to proper fitting of samples into the measurement tube.

Crude palm fibres were prepared in order to test their sound absorbing effectiveness. The fibers were compressed and placed into the pre fabricated moulds. All samples were made fabricated using the same material compositions including the matrix granular part the raw materials which came in the form of rectangular panel were cut into suitable circular shape to fit into the impedance tube. The samples were prepared using latex. The samples were prepared with different thicknesses of $20 \mathrm{~mm}, 30 \mathrm{~mm}, 40 \mathrm{~mm}$ and $50 \mathrm{~mm}$.

For another testing different in period time for compression same thickness of $35 \mathrm{~mm}$ with different densities was also prepared. These samples were designed from the date palm fibre and being utilized as sound absorption sample.

The tests were performed in accordance to ASTM E1050 -98 international standards and they were using microphones GRAS 26 AK, noise generator, amplifier and symphony Dual -channel Real Time Acquisition Unit. The test results were as follows:

Test: The normal incidence of acoustic absorption is the rate of absorption coefficient, which is between (01) at any defined frequencies. It is theoretically the percentage of sound energy absorbed by the fibre sample with value of 1 as fully or 100 percent of the sound being absorbed by the sample. The absorption method for substances, which is meant main indicator for reaction in every environment, is given. The tests conducted in impedance tube according to ASTM E1050-98 international standards validate the measurement. Figure 1 shows the impedance tube facilities. Figure 2 shows date palm fibre test samples various thicknesses.

The impedance tube set consists of two tubes, one for low frequency $100 \mathrm{~mm}$ diameter and another for higher frequency $28 \mathrm{~mm}$ diameter. For testing, the small diameter tubes are connected can be mounted for high frequency measurements which can also act as stand alone with its own loudspeaker case. The microphones are connected to the PC, which also includes a random noise generator. 

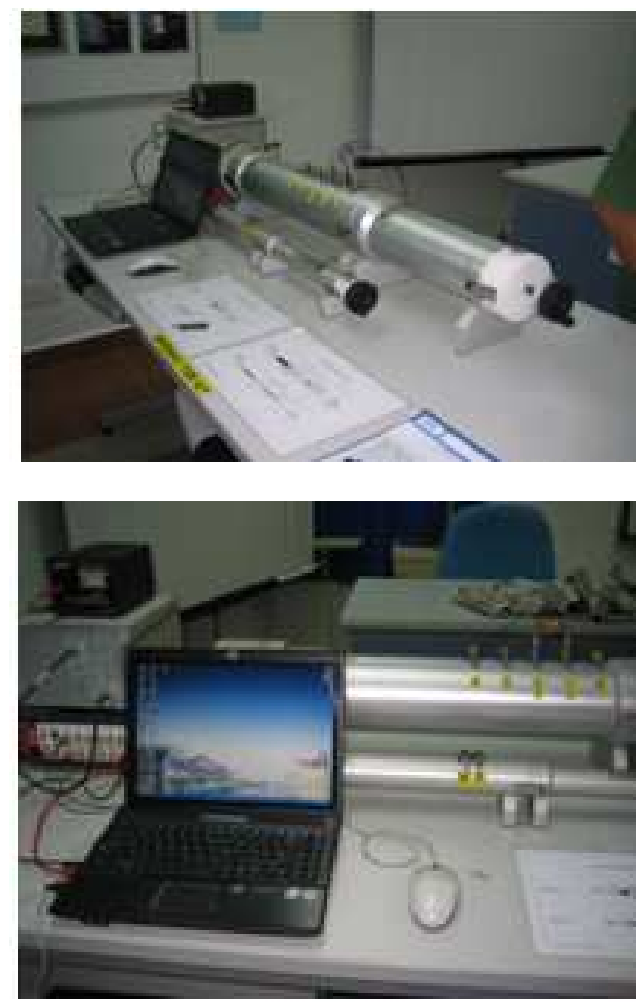

Fig. 1: Impedance tube instrument and set-up for acoustic characteristic

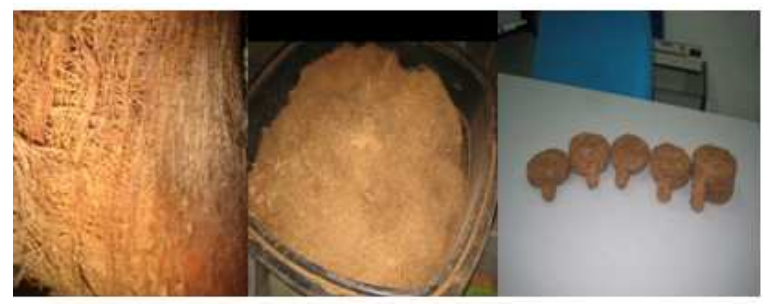

Fig. 2: The date palm fibre: A-crude palm fibre bchopping fibre c- test samples of with different thicknesses $(100,28 \mathrm{~mm})$

Other instruments that were used are loudspeakers case and audio amplifier, microphones and power supply sets. Or alternatively bigger tube can be mounted low frequency measurements. For translating sound wave to digital signal, SCS 8100 software, was used to save the output signal data.

\section{RESULTS}

The results of measurements are presented in Fig. 3-6. These measurements were undertaken using impedance tube at frequency between $87.5 \mathrm{H}$ to $5 \mathrm{KHz}$ for date palm fibre without any backing. The comparison of Acoustic Absorption Coefficient (AAC) was done at different thickness, densities, as well as different compression time during date palm fibre sample making process.

\section{DISCUSSION}

Effect of thickness layer and compression: From Fig. 3, it shows that at low frequencies acoustic absorption coefficient generally increased with the increase in sample thicknesses, but at high frequencies the trends are slightly different with few highs and lows. The dip between frequencies of $3000 \mathrm{~Hz}$ to $4000 \mathrm{~Hz}$ means that the sound is not dissipated and travels through the fibre (Zent and John 2007). Another reason for the dip at mid range frequency band is due to sample irregularity and lack of stiffness since latex is not been used during the sample making process. Hence and the samples appears to be irregular due to the lack of cohesion with latex fibre to add stiffness (Zulkifli et al., 2010).The maximum acoustic absorption coefficient from the test with the corresponding frequencies are shown in Table 1. The results indicated that any thickness increase of fibre leads to increase in AAC due to an increase of its porosity.

Findings of latex and compression process which appear in Fig. 4 indicated on increasing of AAC for all thicknesses samples at low frequency. This is physical parameters such as porosity, tortuosity and flow resistivity after compressing which are given homogenous shape with decreased porosity versus mounted in flow resistivity (Nor et al., 2010). Two peak values for $50 \mathrm{~mm}$ thickness specimen are recorded for high frequency range. AAC values are 0.93 at $1356 \mathrm{~Hz}$ and 0.99 at $4200 \mathrm{~Hz}$ to $4353 \mathrm{~Hz}$. The compression between two Fig. 3 and 4, increase rate of acoustic absorption coefficient AAC in shift frequencies than Fig. 3. This differences due to porous material compressing which appear clearly at all frequencies range (Lee and Chen 2001), (Wang et al., 2008). Drop of $\mathrm{AAC}$ at frequency $1765-2725 \mathrm{~Hz}$ with value 0.67 indicated is poor in mid frequency.

Effect of densities at same thickness: The outcomes data mentioned for two samples have the same thickness $35 \mathrm{~mm}$ in Fig. 5. Nevertheless, increased of density will be given higher value of AAC especially at higher frequency, but identical value of AAC in low frequency range. The maximum value of AAC is 0.83 at $2000 \mathrm{~Hz}$ for large density sample. While, the maximum value of AAC is 0.6 for small density sample in same frequency. Although, in Fig. 6 has been observed the maximum value of AAC at high frequency is 0.84 between $2443.75 \mathrm{~Hz}$ to $2587.5 \mathrm{~Hz}$. This is the better value of AAC, also better value for density compared with Fig. 5. 


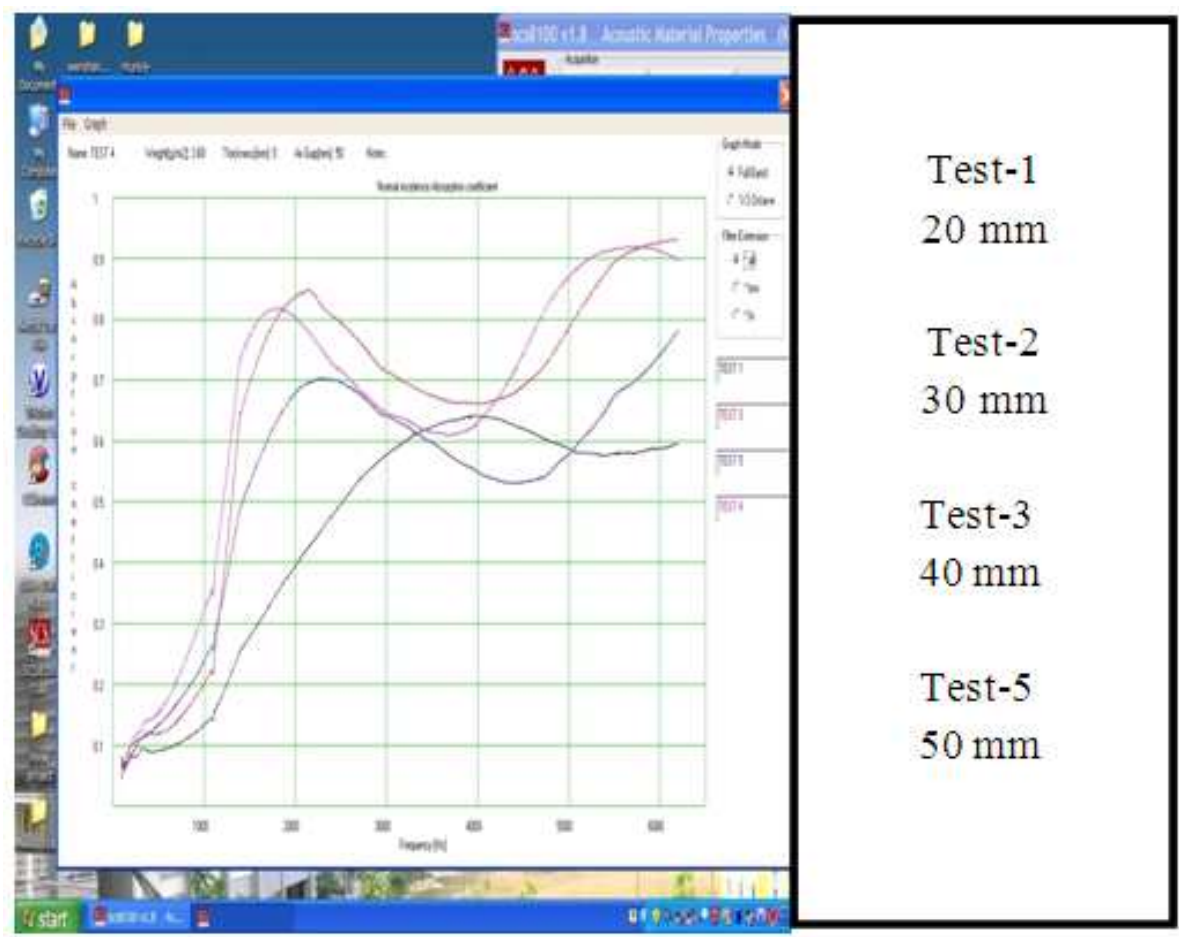

Fig. 3: AAC of comparison between different thickness layers of date palm fibre (20, 30, 40, $50 \mathrm{~mm}$ ) without latex

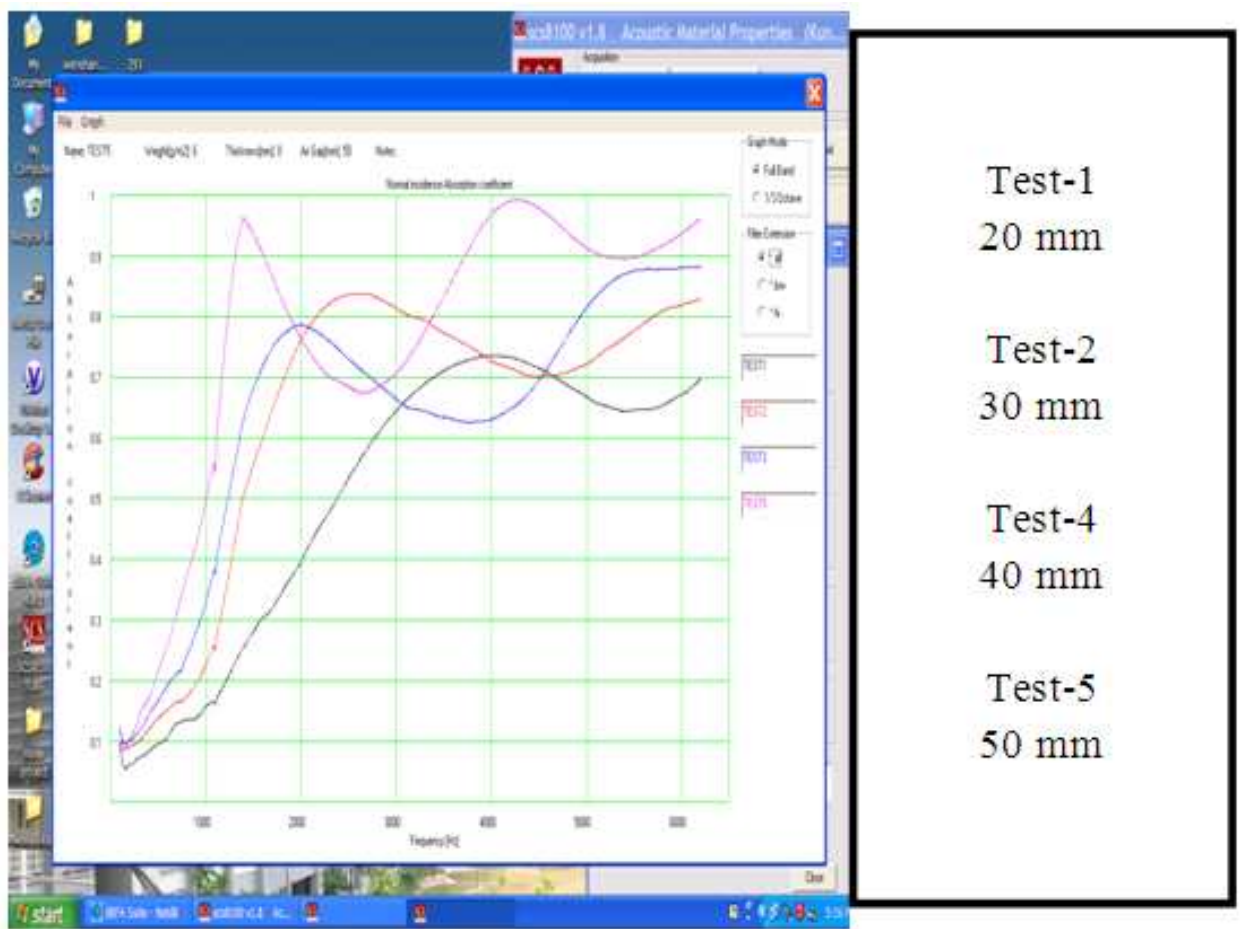

Fig. 4: AAC of comparison between different thickness of date palm fibre $(20,30,40,50 \mathrm{~mm})$ with latex and compression process 


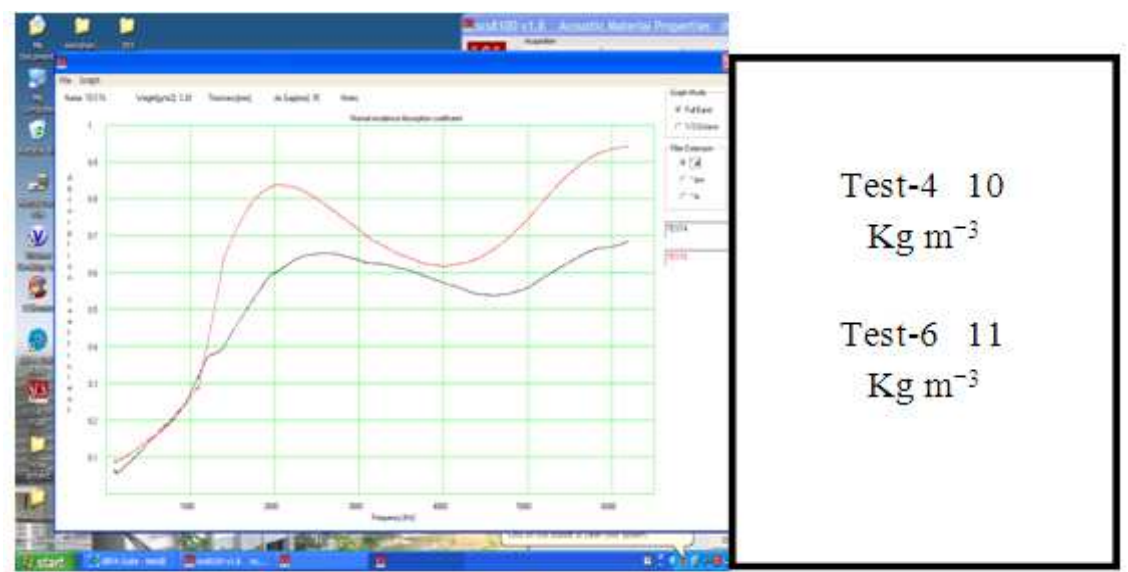

Fig. 5: AAC of comparison between different densities of date palm fibre sample without backing with the thickness layer of $35 \mathrm{~mm}\left(10,11 \mathrm{Kg} \mathrm{m}^{-3}\right)$ compress time $5 \mathrm{~min}$
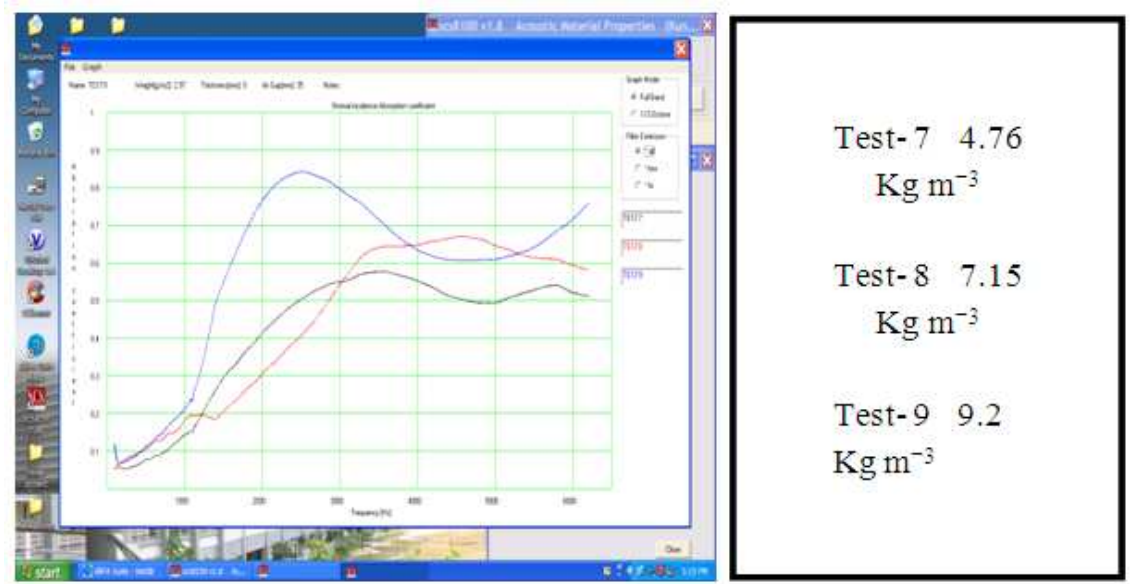

Fig. 6: AAC of comparison between different densities of date palm fibre without backing with thickness layer of $35 \mathrm{~mm}\left(4.76,7.15,9.2 \mathrm{Kg} \mathrm{m}^{-3}\right)$ compress time $7 \mathrm{~min}$

Table 1:The maximum acoustic absorption coefficient at various thicknesses samples

\begin{tabular}{llc}
\hline $\begin{array}{l}\text { Thickness } \\
\text { of fibre } \mathrm{mm}\end{array}$ & $\begin{array}{l}\text { Frequency } \\
\mathrm{Hz}\end{array}$ & $\begin{array}{l}\text { Acoustic } \\
\text { absorption coefficient }\end{array}$ \\
\hline 20 & 3884 & 0.64 \\
30 & $4978-5000$ & 0.83 \\
40 & $4950-5000$ & 0.84 \\
50 & $4950-5000$ & 0.86 \\
\hline
\end{tabular}

Therefore, the advantages to decrease density sample, which is enhanced acoustic absorption coefficient significantly. At the same time, increasing compression period for samples causes changing in physical parameters such as flow resistivity (Nor et al., 2010).

\section{CONCLUSION}

Date palm fibre has been introduced as one of the sound absorber in this study. The results from the experimental tests show that it has good acoustic properties at low and high frequencies and can be used as an alternative replacement to synthetic based commercial product. Samples with various thicknesses, as well as samples with the same thickness but with different densities were tested. In addition, samples with same properties but having different compression period were also inspected.

The sound absorber panel shows a good potential to be an environmentally friendly product. This innovative sound absorption panel has a huge potential due to the fact that they are cheaper, lighter and environmentally friendly as compared to asbestos and rock wool based synthetic materials. Date palm fibre with thicker layer shows significantly increases in acoustic absorption coefficient at low and high frequencies particularly after the introduction of latex 
due to the increase in stiffness. Based on the experimental data, for certain thickness of specimen an increase of compression period leads to least density which is more particular experimental

\section{ACKNOWLEDGEMENT}

The authors are grateful to all of the support given by the (MPOB) , and Noise and Vibration Laboratory, Faculty of Mechanical and Manufacturing Engineering, University Tun Hussein Onn Malaysia, (UTHM). The authors are also grateful for any person assists to support this study, especially Mr. Ahmad Helmi Fairuz and Mr. Mohamed Jammry.

\section{REFERENCES}

Davern, W.A., 1977. Perforated facings backed with porous materials as sound absorbers-an experimental study. Applied Acoustics, 10: 85-112. DOI: 10.1016/0003-682X(77)90019-6

Delany, M.E. and E.N. Bazley, 1970. Acoustical properties of fibrous absorbent materials. Applied Acoustics, 3: 105-116. DOI: 10.1016/0003$682 \mathrm{X}(70) 90031-9$

Ersoy, S. and H. Küçük, 2009. Investigation of industrial tea-leaf-fibre waste material for its sound absorption properties. Applied Acoustics, 70: 215220. DOI: 10.1016/j.apacoust.2007.12.005

Hong, Z., L. Bo and H. Jia, 2007. A novel composite sound absorber with recycled rubber particles. J. Sound Vibration, 304: 400-406. DOI: 10.1016/j.jsv.2007.02.024

Joshi, S.V., L.T. Drzal, A.K. Mohanty and S. Arora, 2004. Are natural fiber composites environmentally superior to glass fiber reinforced composites. Composites Part A: Applied Sci. Manufactur., 35: 371-376. DOI: 10.1016/j.compositesa.2003.09.016
Khedari, J., S. Charoenvai and J. Hirunlabh, 2003. New insulating particleboards from durian peel and coconut coir. Build. Environ., 38: 435-441. DOI: 10.1016/S0360-1323(02)00030-6

Lee, F.C. and W.H. Chen, 2001. Acoustic transmission analysis of multi-layer absorbers. J. Sound Vibration, 248: 621-634. DOI: 10.1006/jsvi.2001.3825

Lee, J. and G.W. Swenson, 1992. Compact sound absorbers for low frequencies. Noise Control Eng. J., 38: 109-117. DOI:

Nor, M.J.M., M. Ayub, R. Zulkifli, N. Amin and M.H. Fouladi, 2010. Effect of different factors on the acoustic absorption of coir fiber. J. Applied Sci., 10: 2887-2892.

Wang, C.N. and J.H. Torng, 2001. Experimental study of the absorption characteristics of some porous fibrous materials. Applied Acoustics, 62: 447-459. DOI: $10.1016 / \mathrm{S} 0003-682 \mathrm{X}(00) 00043-8$

Wang, C.N., Y.M. Kuo and S.K. Chen, 2008. Effects of compression on the sound absorption of porous materials with an elastic frame. Applied Acoustics, 69: 31-39. DOI: 10.1016/j.apacoust.2006.08.006

Wassilieff, C., 2003. Sound absorption of wood-based materials. Appl. Acoustics, 48: 339-356. DOI: 10.1016/0003-682X(96)00013-8

Yang, H.S., D.J. Kim and H.J. Kim, 2003. Rice strawwood particle composite for sound absorbing wooden construction materials. Bioresource Technol., 86: 117-121. PMID: 12653275

Zent, A. and J.T. Long, 2007. Automotive sound absorbing material survey results. SAE International.

Zulkifli, R., M.J.M. Nor, M.F.M. Tahir, A.R. Ismail and M.Z. Nuawi, 2008. Noise control using coconut coir fiber sound absorber with porous layer backing and perforated panel. Am. J. Applied Sci., 7: 260-264. DOI: 10.3844/ajassp.2010.260.264 